\title{
АНАЛИЗ ПРИБЫЛИ И РЕНТАБЕЛЬНОСТИ ОРГАНИЗАЦИЙ, ОСУЩЕСТВЛЯЮЩИХ ДЕЯТЕЛЬНОСТЬ В ОБЛАСТИ ИНФОРМАЦИОННЫХ ТЕХНОЛОГИЙ
}

\author{
(c) 2020 Коркмазов Мурат Хасанович \\ аспирант \\ Финансовый университет при Правительстве Российской Федерации, Россия, Москва \\ E-mail:murat_korkmazov@mail.ru \\ https://orcid.org/0000-0001-5024-7915 \\ (c) 2020 Байрамкулов Магомед Алиевич \\ магистрант \\ Финансовый университет при Правительстве Российской Федерации, Россия, Москва \\ E-mail: bayramkulov09@gmail.com \\ https://orcid.org/0000-0002-6340-7073

\section{(c) 2020 Байрамуков Локман Хусеинович} \\ Магистрант \\ Финансовый университет при Правительстве Российской Федерации, Россия, Москва \\ E-mail: lokman.bayramukov@gmail.com \\ https://orcid.org/0000-0002-7518-8656
}

Предмет/тема: Исследование направлено на изучение показателей прибыли, рентабельности и путей их повышения в организациях, осуществляющих деятельность в области информационных технологий.

Цели/задачи: выявление факторов, оказывающих влияние на величину прибыли и рентабельности и путей их повышения, трендовый анализ показателей прибыли и рентабельности ИТ компаний, изучение показателей рентабельности.

Методология: в процессе исследования были применены методы теоретического исследования, методы статистического анализа (трендовый, регрессионный, корреляционный).

Результаты/выводы: в ходе проведения исследования были раскрыты теоретические аспекты прибыли и рентабельности, раскрыта сущность факторов, оказывающих влияние на формирование данных показателей. Был проведен статистический анализ (трендовый, регрессионный, корреляционный) выборки организаций, осуществляющих деятельность в области информационных технологий на основе рентабельности продаж.

Ключевые слова: прибыль и рентабельность, выборка, пути повышения эффективность организации, корреляция, тренды, выборка, ряд распределения, рентабельность продаж, информационные технологии, управление бизнесом.

Основным фактором благополучия организации является эффективное управление бизнесом, рациональное управление ресурсами, расширение деятельности. Основными показателями, которые характеризуют эффективность деятельности организации, являются прибыль и рентабельность.

Структура и специфика формирования прибыли занимает определяющее место в принятии управленческих решений. Финансовые результаты деятельности организации характеризуют- ся суммой полученной прибыли и уровнем рентабельности. Организации, осуществляющие деятельность в области информационных технологий, получают прибыль, главным образом, от оказания определенных услуг. Таким образом, объем оказанных услуг, реализации товаров, величина прибыли, а также уровень рентабельности характеризуют различные стороны хозяйственной деятельности предприятия.

Определяющую роль в современных условиях перехода от плановой экономики к рыноч- 
ной экономике занимает такая категория, как прибыль. Прибыль - это показатель, характеризующий производственно-хозяйственную деятельность всего предприятия, и является фундаментом для экономического развития организации. Согласно современной экономической теории, рост прибыли создает условия для расширенного воспроизводства, путем формирования основы для самофинансирования деятельности организации.

Основную часть прибыли организации в отрасли ИТ получают от реализации продукции и оказания услуг. Из этого следует, что сумма прибыли зависит от воздействия различных, многочисленных факторов. К таким фактором можно отнести, например: качество, ассортимент, цена, объем реализации, себестоимость, структура и специфика произведенной, реализованной продукции и оказанной услуги и т.д.

Очевидно, что прибыль играет огромную роль в жизни организаций. Фактически этот показатель раскрывает все недостатки производственно-хозяйственной деятельности организаций и является индикатором «здоровья» организаций, в том числе и в отрасли информационных технологий. Руководители предприятий стараются разобраться какие именно факторы оказывают воздействие на прибыль и стараются на эти факторы воздействовать, однако предприятие может влиять не на все факторы.

Прибыль определяется как разность между доходами и осуществленными расходами в процессе производственно-хозяйственной деятельности. Т.е. она определяется через соизмерение доходов и расходов. Этот показатель выступает в самых различных видах и формах.

Рассмотрим основные виды прибыли. Для характеристики деятельности организации от производства и сбыта используется валовая прибыль.

На валовую прибыль оказывают влияние ряд факторов:

- Структура продукции;

- Объем реализации;

- Цены, по которым продукцию или услугу реализует организация;

- Закупочная стоимость материалов, а также комплектующих изделий;

- Итоговое значение расходов на логистику и энергию;

- Расходы на заработную плату и т.д.

Балансовая прибыль - это прибыль (убы- ток) до налогообложения, полученная предприятием от всех видов хозяйственной деятельности (как от обычных видов деятельности, так и от прочих доходов) за определенный период и отраженная в бухгалтерской отчетности. Прибыль до налогообложения - это разница между валовой прибылью и расходами непроизводственного назначения, к которым относятся административно-управленческие расходы и расходы по сбыту произведенной продукции. Таким образом, чистую прибыль можно определить путем вычитания величины налога на прибыль из балансовой прибыли.

Для успешного ведения бизнеса, самофинансирования и для финансовой устойчивости организации требуется прибыль. Чем больше прибыли, полученной организацией, остается в ее распоряжении, тем меньше потребность в привлечении средств из заемных источников, тем выше уровень ее самофинансирования и финансовой устойчивости.

Прибыль имеет свои собственные источники формирования. Выделяют несколько ключевых источников формирования прибыли:

1) Можно выделить такой источник как монопольный выпуск продукции. Т.е. продукт компании является единственным на рынке и не существует у организации конкурентов. При данном подходе у компании не бывает «залежалых» товаров и можно обеспечить бесперебойный товарооборот. Данный источник дохода один из самых эффективных и прибыльных, однако данная организация постоянно должна учитывать антимонопольную политику государства и постоянно учитывать рост конкуренции со стороны других организаций;

2) Второй аспект касается предприятий всех отраслей, а в особенности организации, осуществляющих деятельность в области информационных технологий. Этот источник состоит в владении информации о рынке, конъектуре рынка, основных трендах, потребительском спросе, и емкости рынка для успешной реализации своей продукции. Подобный анализ предоставляет возможность для решения о выходе или приостановке выхода на рынок с определенным товаром и или услугой.

3) Существует два способа для увеличения прибыли. Первый способ включает максимизацию прибыли путем увеличения объемов реализации товаров, услуг. А второй способ включает в себя сокращение средних издержек. В зависимо- 
сти от отраслей существует множество способов сокращения средних общих издержек, но для отрасли информационных технологий многие из них мало применимы. Для отрасли ИТ применимы способы вроде модернизации товаров и услуг и снижение себестоимости продукции за счет снижения фонда заработной платы, экономии на качестве оказываемых услуг, снижения транзакционных издержек и т.д.

Можно выделить следующие резервы прибыли: снижение себестоимости; повышение цен; увеличение объема реализации; реализация в более оптимальные сроки; поиск более выгодных рынков; повышение качества продукции.

Выделяют и иные способы увеличения прибыли. К ним относится инвестиционная деятельность организаций. Компани при наличии свободных денежных средств ищут способы их увеличения самым различными способами. Нередко используется способ инвестирования в другие компании для получения дивидендов, в случае портфельных инвестиций, либо для получения права голоса в инвестируемой компании, в случае стратегического инвестирования. К инвестиционной деятельности также относят инвестиции в недвижимость, драгоценные металлы и т.д. Но стоит отдельно выделить инвестиции в собственную деятельность, то есть модернизация и увеличения эффективности производства. Это все снижает себестоимость продукции и увеличивает прибыль.

Отдельно выделяют финансовую деятельность организаций. Эта деятельность организации, направленная на получение дополнительных доходов помимо доходов, получаемых от основного вида деятельности организации. К такому виду деятельности можно отнести: вклады в банки под проценты, вклады в паевые инвестиционные фонды, инвестирование на рынке форекс и т.д.

Для анализа финансово-хозяйственной деятельности недостаточно только анализировать прибыль и источники его формирования. Следует отметить, что существует понятие рентабельности. Этот показатель является отношением прибыли к стоимости основных средств, к капиталу.

При доступе к бухгалтерской (финансовой) отчетности стейкхолдеры организации имеют возможность анализа финансовой деятельно- сти организации. Они в основном смотрят на уровень рентабельности, как основной способ анализа эффективности вложенного капитала, также эффективности использования имеющихся активов. Существуют несколько способов. Рост любого из показателей зависит от единых взаимосвязанных и взаимозависимых явлений. В первую очередь, стоит смотреть на совершенствование системы управления организацией в условиях нестабильности рынка и, следствие преодоление кризиса финансово-кредитной и денежной системах.

Доходность капитала (один из показателей рентабельности) исчисляется путем отношения балансовой прибыли к среднегодовой стоимости капитала, инвестированного компанией или к отдельным слагаемым собственного, заемного, основного либо оборотного капитала.

Также для определения устойчивости организации принято рассчитывать запас финансовой прочности. Запас финансовой прочности предприятия - разница между выручкой организации за определенный период и порогом рентабельности для данной организации. Этот порог является индикатором, который показывает от производства какого объема продукции мы можем отказаться, не неся при этом убытки. И на рынке более устойчивыми организациями считаются те, что имеют набольший запас финансовой отчетности.

Для правильного анализа следует изучать показатели рентабельности в динамике нескольких лет и проводить сравнение с компаниями конкурентами в той же области. Подобный сравнительный анализ помогает выявить эталонные компании, средние показатели по отрасли и отраслевые стандарты.

Рентабельность, по своей сути, является результатом влияния технических, экономических факторов. Исходя из этого, можно с помощью рентабельности и факторов на него воздействующих понять какие факторы и каким образом оказали влияние на данный результат. Главной целью анализа рентабельности является выявление количественной зависимости конечных финансовых результатов производственнойхозяйственной деятельности организации от основных технико-экономических факторов.

Показатели рентабельности основной источник характеристики среды формирования прибыли и дохода предприятия. Вот почему по- 
казатели рентабельности так необходимы для оценки эффективности работы и сравнительного анализа деятельности и финансового положения предприятия. Стоить отметить, что при анализе показатели рентабельности выполняют роль инструментов ценообразования и инвестиционной политики.

Рентабельность является показателем, который отражается в относительной форме, в отличие от прибыли, которая является по своей сути абсолютным показателем. Показатели рентабельности могут исчисляться по-разному. Но в основном все сводится, к тому, что рентабельной считается организация, финансовые результаты от деятельности которой покрывает все расходы, а также приносят прибыль. Показатели рентабельности в отличие от прибыли более полно характеризуют результаты хозяйственноэкономической деятельности, так как их величина указывает на соотношение эффекта с наличными или использованными ресурсами. Эти показатели могут характеризовать как деятельность в целом, так и деятельность отдельных подразделений.

Показатели рентабельности можно объединить в следующие группы:

- Рентабельность продаж (индикатор оценки эффективности управления);

- Рентабельность производственных фондов;

- Рентабельность вложения в предприятие (прибыльность хозяйственной деятельности).

Одним из показателей, являющихся индикатором оценки эффективности управления, является рентабельность продаж, который будет далее изучен более подробно.

Для изучения структурной характеристики статистической совокупности россий- ских организаций, осуществляющих деятельность в области информационных технологий, была использована база данных электронной справочно-информационной системы «СПАРК». Критерием отбора организаций являются: вид деятельности - деятельность в области информационных технологий, а также ряд других факторов.

Была проведена группировка организаций, осуществляющих деятельность в области ИТ по уровню рентабельности продаж с использованием формулы Стерджесса.

$$
\begin{aligned}
& \mathrm{n}=1+3,322 * 30=1+3,322 * 1,4771=5,907 \\
& \text { (получаем } 6 \text { групп) }
\end{aligned}
$$

Величина интервала, необходимая для осуществления дальнейшей группировки составляет:

$$
I=\frac{x_{\max }-x_{\min }}{n}=\frac{16,9-7,86}{6}=1,507
$$

где I - величина интервала; $\mathrm{x}_{\max }-$ максимальное значение внутри интервала; $\mathrm{x}_{\min }-$ минимальное значение внутри интервала; $\mathrm{n}$ - количество интервалов.

Размером интервала между группами будет являться значение 1,507 .

Таким образом создаются группы, которые отличаются друг от друга уровнем рентабельности продаж и создаются интервальные границы группировки, и исходя из этого уже строятся статистические ряды распределения, представленные в таблице 1.

Из данных выбранной совокупности необходимо найти средние величины. Средние величины дают обобщенную характеристику совокупности по определенному признаку.

Таблица 1. Распределение организаций, осуществляющих деятельность в области ИТ по рентабельности продаж (структурная группировка)

\begin{tabular}{|c|c|c|c|c|c|}
\hline \multirow{2}{*}{ № группы } & \multirow{2}{*}{$\begin{array}{c}\text { Группы } \\
\text { организаций }\end{array}$} & \multicolumn{2}{|c|}{ Количество организаций } & \multirow{2}{*}{$\begin{array}{c}\text { Накопленная } \\
\text { частота }\end{array}$} & $\begin{array}{c}\text { Накопленная } \\
\text { частота, \% }\end{array}$ \\
\cline { 3 - 4 } & $7,86-9,37$ & 5 & 16,7 & 5 & 16,7 \\
\hline 1 & $9,37-10,87$ & 7 & 23,3 & 12 & 40 \\
\hline 3 & $10,87-12,38$ & 4 & 13,3 & 16 & 53,3 \\
\hline 4 & $12,38-13,89$ & 5 & 16,7 & 21 & 70 \\
\hline 5 & $13,89-15,39$ & 5 & 16,7 & 26 & 86,7 \\
\hline 6 & $15,39-16,90$ & 4 & 13,3 & 30 & 100 \\
\hline
\end{tabular}

Источник: составлено автором на основании базы данных информационной базы «СПАРК» 
Необходимо найти среднюю арифметическую, используя формулу средней арифметической взвешенной.

$\overline{\mathrm{x}}_{\mathrm{ap}}=\frac{\sum x_{i} f_{i}}{\sum f_{i}}=\frac{8,61 * 5+10,12 * 7+11,63 * 4+13,13 * 5+14,64 * 5+16,9 * 4}{5+7+4+5+5+4}=\frac{366,86}{30}=12,23$

где $\overline{\mathrm{x}}_{\mathrm{ap}}-$ средняя арифметическая взвешенная; $\sum \mathrm{f}_{\mathrm{i}}-$ итоговое количество организаций;

Вариация - это различие значений признака у отдельных единиц однородной совокупности, которое возникает под влиянием тех или иных факторов. Для ее оценки надо найти следующие коэффициенты:

1) Размах вариации (4):

$$
R=x_{\max }-x_{\min }=16,9-7,86=9,04
$$

где $R$ - размах вариации; $x_{\max }-$ максимальное значение внутри интервала; $x_{\min }-$ минимальное значение внутри интервала.

2) Коэффициент осцилляции (5):

$$
V_{R}=\frac{R}{\bar{x}} * 100 \%=\frac{9,04}{12,23} * 100 \%=73,917
$$

где $V_{R}$ - коэффициент осцилляции; $R$ - размах вариации; $\bar{x}-$ среднее арифметическое взвешенное.

3) Среднее линейное отклонение(6):

$\bar{L}=\frac{\sum\left|x_{i}-\bar{x}\right| f_{i}}{\sum f_{i}}=\frac{70,5 \%}{30}=2,35 \%$

где $\bar{L}-$ среднее линейное отклонение;

$x_{i}-$ значение показателя

4) Дисперсия - средняя арифметическая из квадратов отклонений конкретных значений. Дисперсию исчисляют по формуле (7):

$$
\sigma^{2}=\frac{\sum\left(x_{i}-\bar{x}\right)^{2} f_{i}}{\sum f_{i}}=\frac{218,48 \%}{30}=7,283 \%
$$

где $\sigma^{2}-$ дисперсия.

5) Среднее квадратическое отклонениекорень из среднего квадрата отклонений вариантов от их средней величины. Среднее квадратическое отклонение исчисляют по формуле (8):

$6=\sqrt{\frac{\sum\left(x_{i}-\bar{x}\right)^{2} f_{i}}{\sum f_{i}}}=\sqrt{\frac{218,48}{30}}=\sqrt{7,28}=2,698 \%$

где 6 - Среднее квадратическое отклонение.
6) Коэффициент вариации случайной величины - мера относительного разброса случайной величины. Коэффициент вариации указывает на то, какую долю среднего значения этой величины составляет её средний разброс. Исчисляется в процентах и исчисляется по формуле (9):

$$
\mathrm{V}_{6}=\frac{\sigma}{\bar{x}} * 100 \%=\frac{2,698}{12,23} * 100 \%=22,06 \%
$$

где $\mathrm{V}_{б}-$ Коэффициент вариации случайной величины.

Из данного анализа интервального ряда распределения совокупности организаций, осуществляющих деятельность в области ИТ по рентабельности продаж, можно сделать следующие выводы:

- средний размер показателя рентабельности продаж в данной совокупности равен 12,23\%;

- отклонение среднего квадрата от их средней величины небольшое, а именно равно $2,698 \%$;

- коэффициент вариации равен 22,06\%, и следует вывод о том, что значения в группировке однородны.

По данным таблицы рассчитывается мода ряда распределения. Модальным интервалом является интервал 9,37-10,87, так как ему соответствует наибольшая частота (f=7шт.). А величина данного интервала равна 1,51. В интервальном вариационном ряду с равными интервалами мода исчисляется по формуле (10):

$$
\begin{aligned}
& M_{0}=x_{M o}+d \frac{f_{M o}-f_{M o-1}}{\left(f_{M o}-f_{M o-1}\right)+\left(f_{M o}-f_{M o+1}\right)} \\
& =9,37+1,51 * \frac{7-5}{(7-5)+(7-4)}=9,973 \%
\end{aligned}
$$

где $M_{0}-$ мода; $\mathrm{d}$ - величина модального интервала; $f_{M o}$ - частота модального интервала; $f_{M o-1}$ - частота интервала, предшествующего модальному; $f_{M o+1}-$ частота интервала, находящегося после модального.

Таким образом, в данной выборочной совокупности больше всего встречаются организа- 
ции, осуществляющие деятельность в области информационных технологий с рентабельностью продаж 9,973\%.

Медиана требуется для определения середины выборки, то есть это значение, которое делит вариационный ряд ровно на две части. Чтобы найти порядковый номер медианы, необходимо разделить количество предприятий на два.

$$
N_{M e}=\frac{\sum f_{i}}{2}=\frac{30}{2}=15
$$

где $N_{M e}-$ номер медианы; $\Sigma f_{i}-$ количество организаций.

Построим ряд накопленных частот. Первым числом, превышающим число 15, является 16 . Следовательно необходим медианный интервал 10,87-12,38. В интервальном вариационном ряду медиана исчисляется по формуле (12):

$$
\begin{aligned}
& \mathrm{M}_{\mathrm{E}}=x_{M e}+d \frac{\frac{\Sigma f_{i}}{2}-S_{M e-1}}{f_{M e}} \\
& =10,87+1,51 * \frac{15-12}{4}=12,001 \%
\end{aligned}
$$

где $\mathrm{M}_{\mathrm{E}}$ - медиана; $x_{M e}-$ нижняя граница медианного интервала; - величина медианного интервала; $S_{M e-1}$ - сумма накопленных частот до медианного интервала; $f_{M e}$ - частота медианного интервала.

Значение медианы указывает на то, что половина организаций из выбранной совокупности имеет рентабельность продаж, не превышающую $12,001 \%$.

Проведенные расчеты показали, что средняя величина выпуска продукции предприятий изучаемой совокупности составила $12,229 \%$., при средней квадратическом отклонении 2,698\%. ед., коэффициент вариации составил $22,06 \%$.

Это означает, что совокупность однородна по изучаемому признаку. Наиболее часто встречаются предприятия с уровнем рентабельности продаж равной 9,973\%, а также у 50\% организаций уровень рентабельности продаж более 12,001 .

В компаниях выбранной совокупности существует прямая зависимость между себестоимостью продаж и чистой прибылью. Это можно объяснить тем, что при увеличении затрат на производство, на реализацию продукции, услуг, увеличиваются и объемы реализации продукции, услуг. Следовательно, увеличивается и чистая прибыль. И тем самым связь между факторным показателем, т.е. себестоимостью продаж, и результативным показателем, т.е. чистой прибылью прямая. Далее следует найти тесноту взаимосвязи с помощью коэффициента корреляции и корреляционного отношения.

Для оценки степени тесноты связи используется линейный коэффициент корреляции. Данный коэффициент изменяется в пределах от -1 до +1 . Интерпретация значений коэффициента корреляции представлена в таблице.

Расчет необходимых показателей для вычисления коэффициента корреляции проведен в таблице 2.

Коэффициент корреляции рассчитывается по формуле (13):

$$
\begin{aligned}
& r=\frac{\sum(x-\bar{x})(y-\bar{y})}{\sqrt{\sum(x-\bar{x})^{2} \sum(y-\bar{y})^{2}}} \\
& =\frac{1993695543}{\sqrt{(16577034018) *(349890327)}}=0,674
\end{aligned}
$$

где $\mathrm{r}$ - коэффициент корреляции;

$\sum(x-\bar{x})(y-\bar{y})-$ стандартное отклонение переменной $\mathrm{x}$;

$\sqrt{\sum(x-\bar{x})^{2} \sum(y-\bar{y})^{2}}-$ стандартное отклонение переменной у.

\section{Таблица 2. Расчет характеристик ряда распределения}

\begin{tabular}{|c|c|c|c|c|c|c|c|c|}
\hline No & $\begin{array}{c}\text { Группа } \\
\text { предприятий } \\
\text { по величине } \\
\text { рентабельно- } \\
\text { сти продаж, } \%\end{array}$ & $\begin{array}{c}\text { Число } \\
\text { организа- } \\
\text { ций (f) }\end{array}$ & $\begin{array}{c}\text { Середина } \\
\text { (х) }\end{array}$ & $\begin{array}{c}\mathrm{x}-\overline{\mathrm{x}} \\
|\mathrm{x}-\overline{\mathrm{x}}|\end{array}$ & $(\mathrm{x}-\overline{\mathrm{x}})^{2}$ & $(\mathrm{x}-\overline{\mathrm{x}})^{2 * \mathrm{f}}$ & $\Sigma$ \\
\hline I & $7,86-9,37$ & 5 & 8,61 & $-3,62$ & 3,62 & 13,11 & 65,55 & 5 \\
\hline II & $9,37-10,87$ & 7 & 10,12 & $-2,11$ & 2,11 & 4,45 & 31,15 & 12 \\
\hline III & $10,87-12,38$ & 4 & 11,63 & $-0,60$ & 0,60 & 0,36 & 1,44 & 16 \\
\hline IV & $12,38-13,89$ & 5 & 13,13 & 0,90 & 0,90 & 0,81 & 4,05 & 21 \\
\hline V & $13,89-15,39$ & 5 & 14,64 & 2,41 & 2,41 & 5,81 & 29,05 & 26 \\
\hline VI & $15,39-16,90$ & 4 & 16,90 & 4,67 & 4,67 & 21,81 & 87,24 & 30 \\
\hline x & Итого & 30 & - & 1,65 & 14,31 & 46,35 & 218,48 & \\
\hline
\end{tabular}

Источник: составлено автором на основании базы данных «СПАРК» 
Линейный коэффициент корреляции равен 0,674. Между величиной себестоимости продаж и суммой чистой прибыли корреляция положительная, то есть при увеличении значения себестоимости продаж, сумма чистой прибыли увеличивается. И в данной исследуемой совокупности корреляция является прямой средней.

После обнаружения прямой средней корреляции следует совершить регрессионный анализ с помощью уравнения регрессии. Уравнение регрессии помогает вычислить числовое соотношение между величинами.

Необходимо найти уравнение регрессии (14):

$$
\hat{y}_{x}=a_{0}+a_{1} x
$$

где $\hat{y}_{x}-$ зависимая переменная; $a_{0}-$ свободный член; $a_{1}-$ угловой коэффициент; $\mathrm{x}-$ независимая переменная.

$$
\left\{\begin{array}{c}
a_{0} n+a_{1} \sum x=\sum y \\
a_{0} \sum x+a_{1} \sum x^{2}=\sum y x
\end{array}\right.
$$

Отсюда, найдя $a_{0}$ и $a_{1}$, получаем уравнение регрессии:

$$
\hat{y}_{x}=3,9915 X+8820
$$

Это уравнение указывает на то, что при увеличении значения себестоимости продаж на 3,9915 млн. руб., чистая прибыль увеличится на 1 млн. руб. На это указывает параметр $a_{1}$, а параметр $a_{0}$, в свою очередь указывает на усредненное влияние неучтенных факторов. Это объясняется тем, что компания при больших тратах на создание продукции, маркетинг, реализацию в дальнейшем реализует большее количество продукции, услуг и получает больше выручки. Соответственно, за вычетом от выручки себестоимости компания получает больше прибыли.
Из этого следует найти средние показателей абсолютного прироста, темпов роста и т.д.

Средний абсолютный прирост равен (15):

$\bar{\Delta}=\frac{\sum \Delta_{i}^{\text {ये }}}{n-1}=\frac{209,93}{3}=69,9778$

где $\Delta_{i}^{\amalg}$ - цепной абсолютный прирост.

Средний темп роста $(\bar{T})$ можно рассчитать по формуле:

$$
\begin{aligned}
& \bar{T}=\sqrt[n-1]{T_{1}^{\text {Ц }} * T_{2}^{\text {Ц }} * \ldots * T_{n}^{\text {Щ }}} \times 100 \% \\
& =\sqrt[2]{0,9387 * 1,1774} \times 100 \%=105,13 \%
\end{aligned}
$$

где $T_{i}^{\amalg}$ - цепной темп роста

Средний темп прироста равен:

$$
\overline{T_{\text {пр }}}=\bar{T}-100=105,8-100=5,8 \%
$$

На основании расчетных данных данной таблицы можно сделать вывод, что средняя чистая прибыль организаций по выбранной, осуществляющих деятельность в области ИТ с 2017 по 2019 увеличилась на 209,93 тыс. рублей и составила 2205,30 тыс. руб.

Проведенный статистический анализ множества показателей дает общее представление об эффективности деятельности организаций, осуществляющих деятельность в области информационных технологий.

На основании проведенного анализа можно сделать следующие выводы:

- за рассматриваемый период средняя величина чистой прибыли по 30 организациям в абсолютном значении увеличилась на 209,93 тысяч рублей, прирост прибыли в среднем по организациям представленной совокупности составил $5,8 \%$;

- выявлена средняя прямая корреляция

\begin{tabular}{|c|c|c|c|c|c|c|c|c|}
\hline \multirow[b]{2}{*}{ Год } & \multirow{2}{*}{$\begin{array}{c}\text { ЧП, } \\
\text { тыс. руб. }\end{array}$} & \multicolumn{2}{|c|}{ Абсолютный прирост } & \multicolumn{2}{|c|}{ Темпы роста,\% } & \multicolumn{2}{|c|}{ Темпы прироста, } & \multirow{2}{*}{$\begin{array}{c}\text { Абсолют. } \\
\text { значение } \\
\text { 1\% приро- } \\
\text { ста }\end{array}$} \\
\hline & & цеп. & баз. & цеп. & баз. & цеп. & баз. & \\
\hline 2017 & 1995,37 & - & - & - & - & - & - & - \\
\hline 2018 & 1873,07 & $-122,30$ & $-122,30$ & 93,87 & 93,87 & $-6,13$ & $-6,13$ & 19,95 \\
\hline 2019 & 2205,30 & 332,23 & 209,93 & 117,74 & 110,52 & 17,74 & 10,52 & 18,73 \\
\hline Итого & & 209,93 & 87,63 & 211,61 & 204,32 & 11,61 & 4,39 & 38,68 \\
\hline
\end{tabular}
между величиной себестоимости продаж и чистой прибылью. Т.е. в среднем по выбранной совокупности, при увеличении значения себе-

Таблица 3. Динамика чистой прибыли по выбранной совокупности / [Dynamics of net profit for the selected population]

Источник: составлено автором на основании базы данных «СПАРК» 
стоимости продаж, величина чистой прибыли растет;

- можно говорить о положительной динамике в целом по выбранной совокупности.

С развитием компаний, осуществляющих деятельность в области ИТ связано эффективность развития всех остальных отраслей экономики, так как оно обеспечивает компаниям конкурентные преимущества, способ автоматизировать данные, оцифровать свои данные и надежно их хранить.

Для проведения анализа показателей прибыли до налогообложения и рентабельности продаж были выбраны 2 организации из статистической совокупности. Названия данных компаний были изменены для написания работы. Компания ООО «А» и 000 «Б».

Выбраны были эти организации, так как показатели рентабельности продаж у них схожи в 2019 году, однако в остальные периоды они значительно отличались. ООО «Б» на протяжении анализируемых 5 лет превосходит компанию ООО «А» по показателю прибыли до налогообложения.

Необходимо отметить, что по состоянию на 2018 год разрыв по показателю прибыли до налогообложения у данных организаций, не являлся столь существенным, что нельзя сказать о ситуации годами ранее. Также стоит отметить, что по состоянию на 2019 год разрыв снова увеличился и составил 3294 тыс. руб. На протяжении всего рассматриваемого периода уровень рентабельности продаж компании ООО «А» является, достаточно, низким по сравнению с отраслевым значением средним значением по отрасли 12,23\% и более, но в 2019 году организации удалось увеличить уровень рентабельности продаж на 237,37\% по сравнению с 2018 г. Рентабельность продаж ООО «А» в 2019 году составила $13,34 \%$ - это на 12,81\%ниже, чем у ООО «Б».

И совсем противоположная ситуация наблюдается у второй организации. Последние несколько лет рентабельность продаж ООО «Б» превышает отраслевое значение данного показателя (за исключением 2018 г.) причем значительно. В 2019 году показатель рентабельности продаж достиг 15,3\%, что является положительной тенденцией после спада в 2017-2018 г.

В ходе изучения динамики чистой прибыли и величины себестоимости продаж была подтверждена прямая связь этих показателей. В соответствии с этим можно сделать вывод о том, что при увеличении себестоимости продаж путем увеличения объема реализованной продукции, увеличении затрат в инфраструктуру, основные средства, отдел продаж, отдел маркетинга, величина чистой прибыли растет. Это свойственно для компании ООО «Б». А для компании ООО «А» характерно снижение значения чистой прибыли при увеличении значения себестоимости продаж. Это означает, что имеет место много неэффективных затрат.

Ранее в работе была выявлена средняя прямая корреляция между величиной себестоимости продаж и чистой прибылью. Т.е. в среднем по выбранной совокупности, при увеличении значения себестоимости продаж, величина чистой прибыли растет. Однако в случае компании ООО «А» данная корреляция имеет меньшее значение (как правило такое бывает из-за неэффективного менеджмента в компании).

Была рассмотрена связь между значением себестоимостью продаж и величиной чистой прибыли. Теперь нам следует проанализировать рентабельность продаж, а также проанализировать факторы, влияющие на рентабельность продаж.

Проведем факторный анализ влияния выручки на рентабельность от продаж, по каждой организации. Начнем с ИТ организации ООО «А», у которой рентабельность от продаж равняется $14,76 \%$.

Далее используется формула определения рентабельности продаж. Это кратная модель. Мы будем использовать метод цепных подстановок, чтобы найти степень влияния факторов

Таблица 4. Исходные данные для факторного анализа рентабельности ОоО «А» за 2018-2019 гг.

\begin{tabular}{|l|c|c|c|c|}
\hline \multirow{2}{*}{\multicolumn{1}{c|}{ Показатель }} & 2018 г. & 2019 г. & $\begin{array}{c}\text { Абсолютное, } \\
\text { (тыс.руб.) }\end{array}$ & $\begin{array}{c}\text { Относительное, } \\
\text { (\%) }\end{array}$ \\
\hline Прибыль от продаж (тыс. руб.) & 12545 & 9691 & -2854 & 77,25 \\
\hline Выручка (тыс. руб.) & 97448 & 65678 & -31770 & 67,398 \\
\hline Рентабельность продаж (\%) & 12,87 & 14,76 & $+1,89$ & 114,69 \\
\hline
\end{tabular}

Источник: составлено автором на основании базы данных «СПАРК» 
на изменение выручки от продаж:

$$
\begin{aligned}
& \mathrm{P}_{\text {п0 }}=\Pi_{\mathrm{p} 2018} / \mathrm{B}_{\mathrm{p} 2018}=12,87 \% . \\
& \mathrm{P}_{\text {пусл }}=\Pi_{\mathrm{p} 2019} / \mathrm{B}_{\mathrm{p} 2018}=9,945 \% . \\
& \mathrm{P}_{\text {п1 }}=\Pi_{\mathrm{p} 2019} / \mathrm{B}_{\mathrm{p} 2019}=14,76 \%
\end{aligned}
$$

1) Степень воздействия величины прибыли на изменение показателя рентабельности от продаж:

$$
\Delta \mathrm{P}_{\Pi}=9,945 \%-12,87 \%=-2,925 \%
$$

2) Степень воздействия величины выручки на изменение рентабельности продаж:

$$
\Delta \mathrm{P}_{\Pi}=14,76 \%-9,945 \%=4,815 \%
$$

Вывод: произошло уменьшение рентабельности на 2,925\% из-за уменьшения величины прибыли на 2854 тыс. руб., а также произошло увеличение рентабельности продаж на 4,815\% из-за уменьшения величины выручки на 31770 тыс. руб. В общем итоге произошло увеличение рентабельности продаж в организации на 1,89\%. Данная факторная модель является наиболее простой, однако она позволяет указать на методологию ее построения и принцип работы.

Далее рассмотрим ИТ организацию ООО «Б». Необходимо использовать ту же модель.

$$
\begin{aligned}
& \mathrm{P}_{\Pi 0}=\Pi_{\mathrm{p} 2018} / \mathrm{B}_{\mathrm{p} 2018}=14,2 \% . \\
& \mathrm{P}_{\text {пусл}}=\Pi_{\mathrm{p} 2019} / \mathrm{B}_{\mathrm{p} 2018}=18,82 \% . \\
& \mathrm{P}_{\Pi 1}=\Pi_{\mathrm{p} 2019} / \mathrm{B}_{\mathrm{p} 2019}=15,7 \%
\end{aligned}
$$

1) Степень воздействия величины прибыли на изменение показателя рентабельности от продаж:

$\Delta \mathrm{P}_{\Pi}=18,82 \%-14,2 \%=4,62 \%$

2) Степень воздействия величины выручки на изменение рентабельности продаж:

$$
\Delta \mathrm{P}_{\Pi}=15,7 \%-18,82 \%=-3,12 \%
$$

Вывод: увеличение величины рентабельности продаж на 4,62\% произошло из-за увеличения прибыли от продаж на 3039 тыс. руб., а также уменьшение рентабельности на 3,12\% произошло из-за увеличения величины выручки на 13060 тыс. руб. В общем, произошло увели- чение рентабельности продаж на 1,5\%.

Для организации ООО «А» рекомендуется мобилизовать все имеющиеся в распоряжении ресурсы, также снизив при этом себестоимость оказываемых услуг и реализуемой продукции. Т.е. рекомендуется избавиться от всех факторов, негативно влияющих на величину чистой прибыли. Также рекомендуется создание более привлекательных для клиентов условий по использованию их услуг для создания конкурентного преимущества.

Одним из путей увеличения чистой прибыли для ООО «Б» будет являться увеличение прибыли от продаж, соответственно стоит уделить внимание проработке отдела продаж и отдела маркетинга в компании. Также можно создать новое программное обеспечение или придумать новую услугу. Если для реализации данной идеи нет у организации соответствующих ресурсов, то можно привлечь инвестиции.

Исходя из всего вышесказанного, можно выделить несколько путей увеличения прибыли и рентабельности:

- снижение себестоимости реализуемой продукции и оказываемой услуги, путем внедрения технологий и усовершенствования организации труда и производства, которые способствуют также и увеличению качества продукции. В тоже время была выявлена при корреляционно- регрессионном анализе средняя прямая связь между показателями себестоимости продаж и чистой прибылью. Это означает, что если компания инвестирует больше денег в выпуск большего количества продукции, оказания услуг, также вкладывает деньги в маркетинг, сбыт и т.д., то в конечном итоге получает больше прибыли. Это говорит о том, что стоит отказаться от неэффективных трат, а стоит более эффективно тратить ресурсы, при этом увеличить количество оказываемых услуг, реализуемых товаров;

- увеличение доли рынка путем выпуска новой продукции, либо выход на новый рынок, увеличение объемов производства путем вкла-

Таблица 5. Исходные данные для факторного анализа рентабельности 000 «Б» за 2018-2019 гг.

\begin{tabular}{|l|c|c|c|c|}
\hline \multirow{2}{*}{\multicolumn{1}{c|}{ Показатель }} & 2018 г. & 2019 г. & $\begin{array}{c}\text { Абсолютное, } \\
\text { (тыс. руб.) }\end{array}$ & $\begin{array}{c}\text { Относительное, } \\
\text { (\%) }\end{array}$ \\
\hline Прибыль от продаж (тыс.руб.) & 9336 & 12375 & +3039 & 132,6 \\
\hline Выручка (тыс.руб.) & 65744 & 78804 & +13060 & 119,9 \\
\hline Рентабельность продаж (\%) & 14,2 & 15,7 & $+1,5$ & 110,6 \\
\hline
\end{tabular}

Источник: составлено автором на основании базы данных «СПАРК» 
дывания либо собственных средств, либо заемных.

На примере двух организаций ООО «А» и ООО «Б» мы проследили влияние факторов на прибыль до налогообложения и рентабельность продаж. Анализ показал, что увеличение значения прибыли до налогообложения по отношению к величине выручки позволяет увеличить показатель рентабельности продаж. А увеличение прибыли при неизменности показателя чистой прибыли наоборот уменьшает показатель рентабельности продаж Т.е. величина себестоимости продаж должно увеличиваться только за счет эффективных затрат, тех затрат, которые увеличивают значение чистой прибыли. К таким затратам можно отнести: В этих компаниях напротив уменьшение себестоимость продаж позволяет увеличить налог до налогообложения.

Мы получили следующие способы увеличения прибыли:

- создание новых товаров, оказание новых видов услуг;

- улучшение качества уже имеющихся товаров, услуг;

- проработка отдела продаж, отдела маркетинга;

- увеличение производственных мощностей, которые помогают ИТ компаниям увели- чить качество оказываемых услуг и т.д.

На основе анализа можно сделать вывод, что в последние два года наблюдается положительная динамика в совокупности, отрасль информационных технологий набирает свои обороты и занимает все более значительную роль в экономике страны.

Исходя из анализадинамики чистой прибыли, было выявлено, что финансово-хозяйственная деятельность организаций, осуществляющих деятельность в области информационных технологий достаточно прибыльна. Была выявлена положительная корреляция между факторным показателем себестоимостью продаж и результативным показателем чистая прибыль, с теснотой связи 0,674 , что говорит о средней прямой связи. Тем самым, организациям, осуществляющим деятельность в области информационных технологий, стоит инвестировать в показатель себестоимости продаж, т.е. увеличивать эффективные затраты на производство продукции, оказание услуг, вкладываться в инфраструктуру, выстроить отдел продаж, выстроить отдел маркетинга, вкладываться в НИОКР. Все эти затраты позволят увеличить клиентскую базу либо увеличить лояльность уже существующих клиентов. И все это в конечном итоге позволит увеличить чистую прибыль.

\section{Библиографический список}

1 Гражданский кодекс Российской Федерации (часть первая) от 21.11.1994 г. № 51-Ф3 (ред. от 16.12.2019) // СПС Консультант плюс.

2 Федеральный закон «Об обществах с ограниченной ответственностью» от 08.02.1998 N 14-Ф3 (последняя редакция) // СПС Консультант плюс.

3 Алексеева, Домбровская, Сафонова (2019) - Алексеева Г. И., Домбровская Е.Н., Сафонова И. В. Финансовый учет и отчетность + Приложение: Тесты (для бакалавров). // Учебник - М: 2019 г.

4 Бариленко, Ефимова, Керимова, Ермакова (2021) - Бариленко В.И., Ефимова О. В., Керимова Ч. В., Ермакова М.Н. Экономический анализ. // Учебник - М: 2021 г.

5 Салин, Чурилова, Шпаковская (2021) - Салин В. Н., Чурилова Э. Ю., Шпаковская Е. П. Статистика (Бакалавриат) // Учебное пособие.- М.: 2021 г.

6 Справочная правовая система (СПС) «Консультант плюс». Электронный ресурс - режим доступа: http:// www.consultant.ru/ 